\title{
A Case Report of Adult Vitelliform Macular Dystrophy.
}

\author{
Dr. Mohd Zeeshan Sayani ${ }^{1}$, Dr. Sudhakar N.A ${ }^{2}$ \\ (Department Of Ophthalmology, K.V.G Medical College And Hospital, Rguhs, India)
}

\begin{abstract}
A 59 Years Old Male Patient Presented With Onset, Gradually Progressive In Nature And Painless. It Was Associated With Metamorphopsia. No H/O Of Similar Complaints In The Family. Bcva Re-20/70 N36, Le-20/30 N6. Ase (Ou)- With In Normal Limit.

Fundoscopy: (Re)-Yellowish Oval Shaped Complaints Of Diminution Of Vision In Right Eye Since 2 Years. It Was Insidious In Lesion In The Macular Area Of About 1.5 Dd Resembling Egg Yolk.(Le) With In Normal Limits.Ffa And Oct Was Advised

Results: Ffa- Showed Typically Hypofluorescence In The Region Of Yellowish Region With Surrounding Ring Of Hyperfluorescence.Oct-Aquired Through The Macular Region Showed Highly Reflective Well Circumscribed Elevation Of Rpe Above A Moderately Reflective Region.

Conclusion: Based On The Above Findings A Diagnosis Of Adult Onset Viteliform Macular Dystrophy (Avmd) Was Made.Patients With Adultonsetmacular Vitelliform Dystrophy Typically Have Slowprogressive Vision Loss. However, Patients Can Develop Dramatically Decreased Vision Owing Tosubfoveal Choroidal Neovascularization (Cnv). Thus, It Is Important To Establish The Correctdiagnosis And Monitor This Condition.
\end{abstract}

Keywords: Avmd, Best Disease, Macular Dystrophy, Pattern Dystrophy, Vitelliform Lesion.

\section{Introduction}

The Classical Vitelliform Macular Lesion Characterises Best's Vitelliform Dystrophy, But In Adults Similar Lesions Are Less Well Categorised.In 1974, Gass ${ }^{1}$ Described A 'Peculiar Foveomacular Dystrophy' Which He Later Termed 'Foveomacularvitelliform Dystrophy: Adult Type ${ }^{2}$. The Hallmark Of The Condition Is A Yellow, Slightly Elevated Lesion, One-Third To One Disc Diameter In Size, And Often With Pigment In The Form Of A Spot, Figure, Or Ring. At Times The Central Pigment Clump Is The Predominant Feature, Surrounded By A Hypopigmented Halo. As A Result, Many Different Terms Have Been Applied To This Picture, Mostly Emphasising The Yellow Vitelliform Lesion, ${ }^{2,3,4}$ Less Commonly The Pigment. ${ }^{5,6,7}$.

A Hereditary Traitassociated With Mutations In Vmd-2 And Rds Gene With Autosomal Dominant Character Has Been Established In Some Cases But Not In Others, So That It Has Variously Been Termed A Degeneration ${ }^{8,9,10}$ Or A Dystrophy., ${ }^{2,3,5,11}$ In This Report It Is Termed Adult Vitelliform Macular Degeneration (Avmd). The Disease May Present Different Phenotypes In The Same Family, ${ }^{12}$ Or In The Two Eyes Of The Same Individual, ${ }^{10,11}$ Or Even In The Same Eye At Different Times. ${ }^{10}$

Vitelliform Lesions Represent The Effects Of Retinalpigment Epithelium (Rpe) Dysfunction With Accumulation Ofdegenerated Photoreceptor Outer Segments In The Subretinal Space. The Onset Of Disease Is Usually $3^{\text {rd }}$ To $6^{\text {th }}$ Decade With Minimal Visual Loss And Metamorphopsia.We Report A Case Of Avmd With Unilateral Presentation.

\section{Case Report}

A 59 Years Old Male Patient Presented With Complaints Of Diminution Of Vision In Right Eye Since 2 Years. It Was Insidious In Onset, Gradually Progressive In Nature And 
Painless.It Was Associated With Metamorphopsias In Amsler Test.No H/O Of Similar Complaints In The Family.Slit Lamp Biomicroscopic Examination (Ou)- With In Normal Limits.

\begin{tabular}{|l|l|l|l|}
\hline & $\begin{array}{l}\text { Bcva (Snellens } \\
\text { Chart) }\end{array}$ & $\begin{array}{l}\text { Colour Vision } \\
\text { (Ishihara Chart) }\end{array}$ & $\begin{array}{l}\text { Iop (Applantation } \\
\text { Tonometry) }\end{array}$ \\
\hline Od & 20/70, N36 & Trichromatic & $14 \mathrm{Mmhg}$ \\
\hline Os & $20 / 30, \mathrm{N6}$ & Trichromatic & $13 \mathrm{Mmhg}$ \\
\hline
\end{tabular}

1. Investigations

1.1 Dilated Fundus Examination

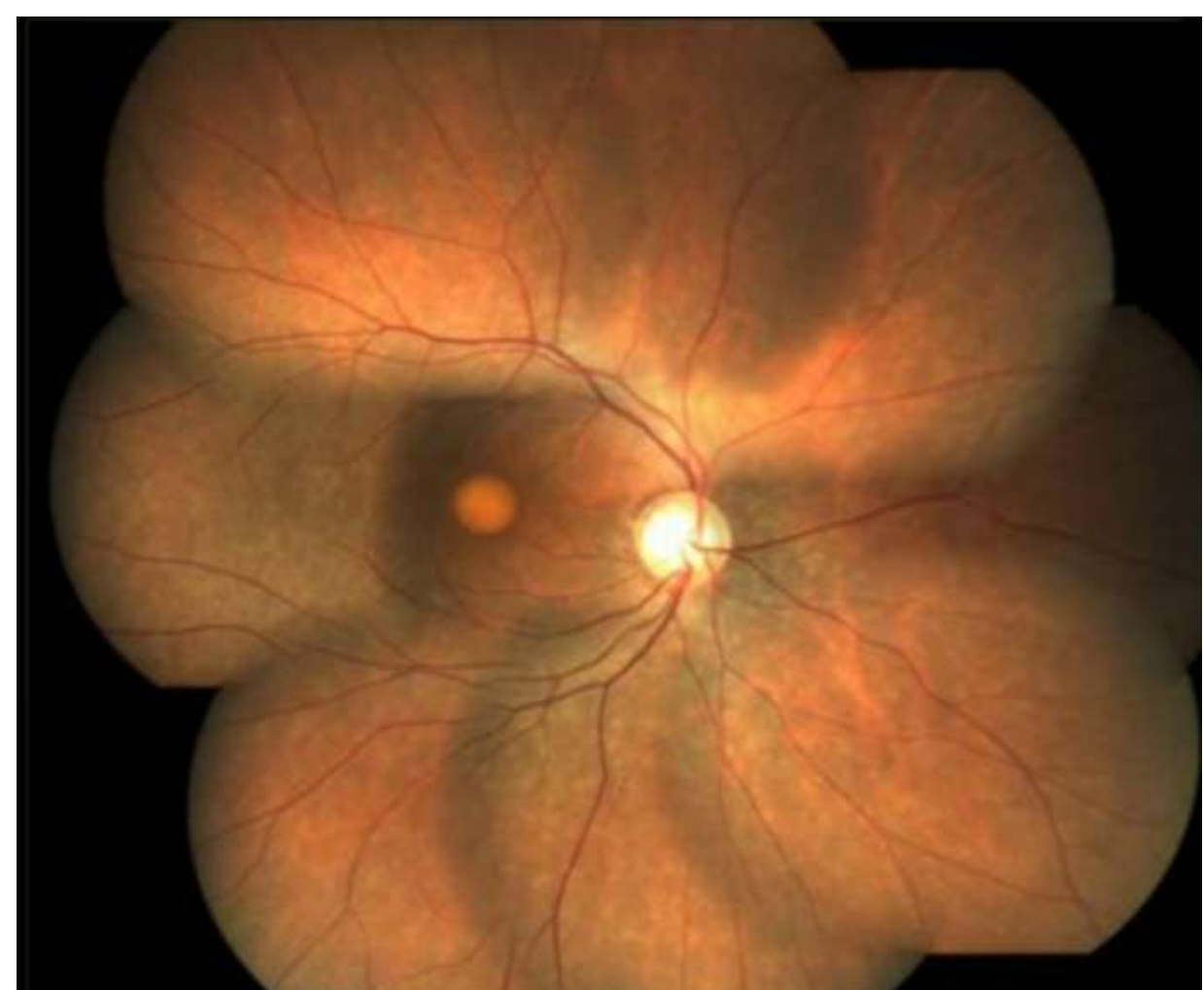

Figure 1: Right Eye-Yellowish Oval Shaped Lesion in the Macular Area of About 1/2 Dd Resembling Egg olk We 


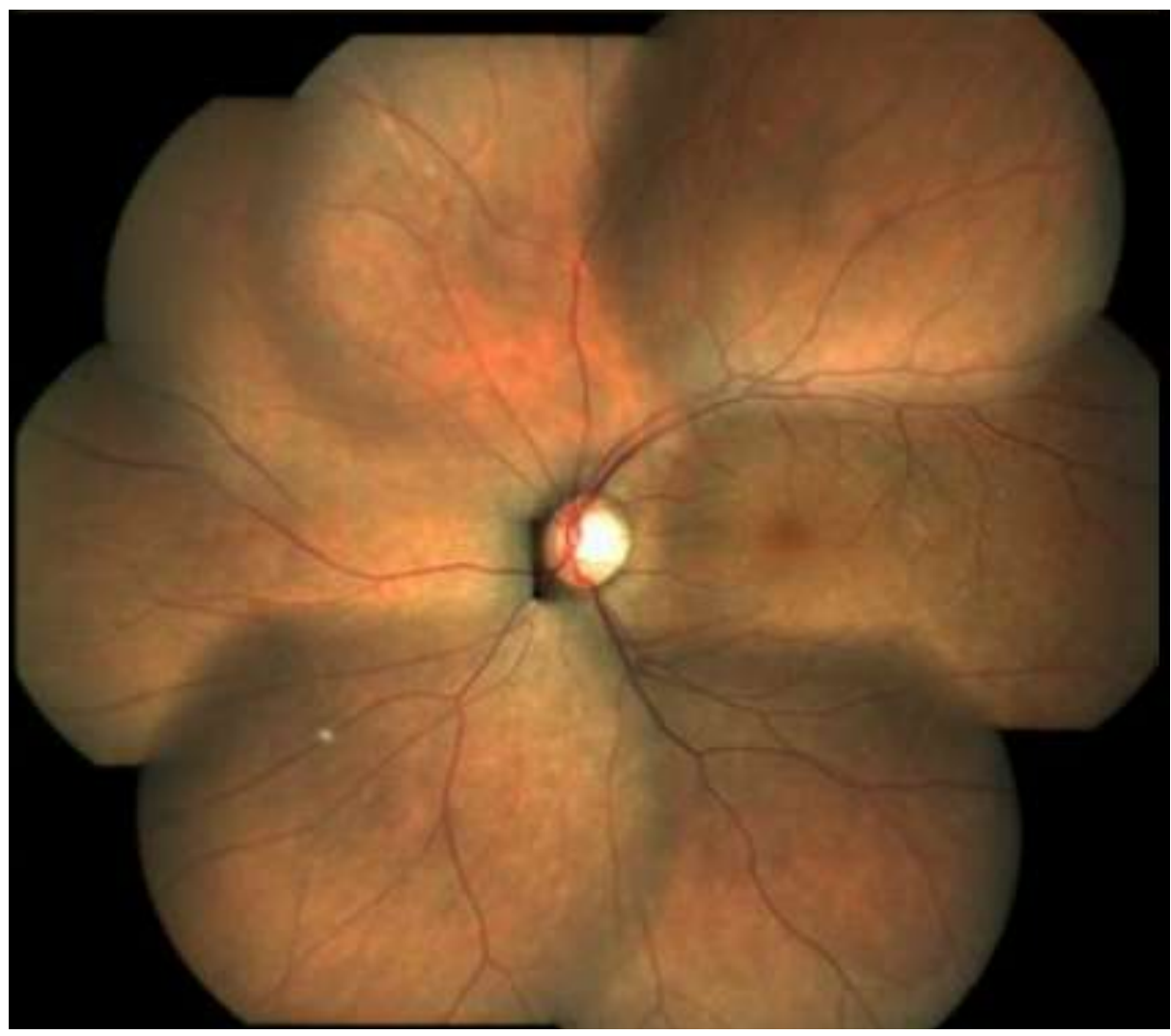

Figure 2: Left Eye- Appears With In Normal Limit

\subsection{Fundus Fluorescein Angiography}

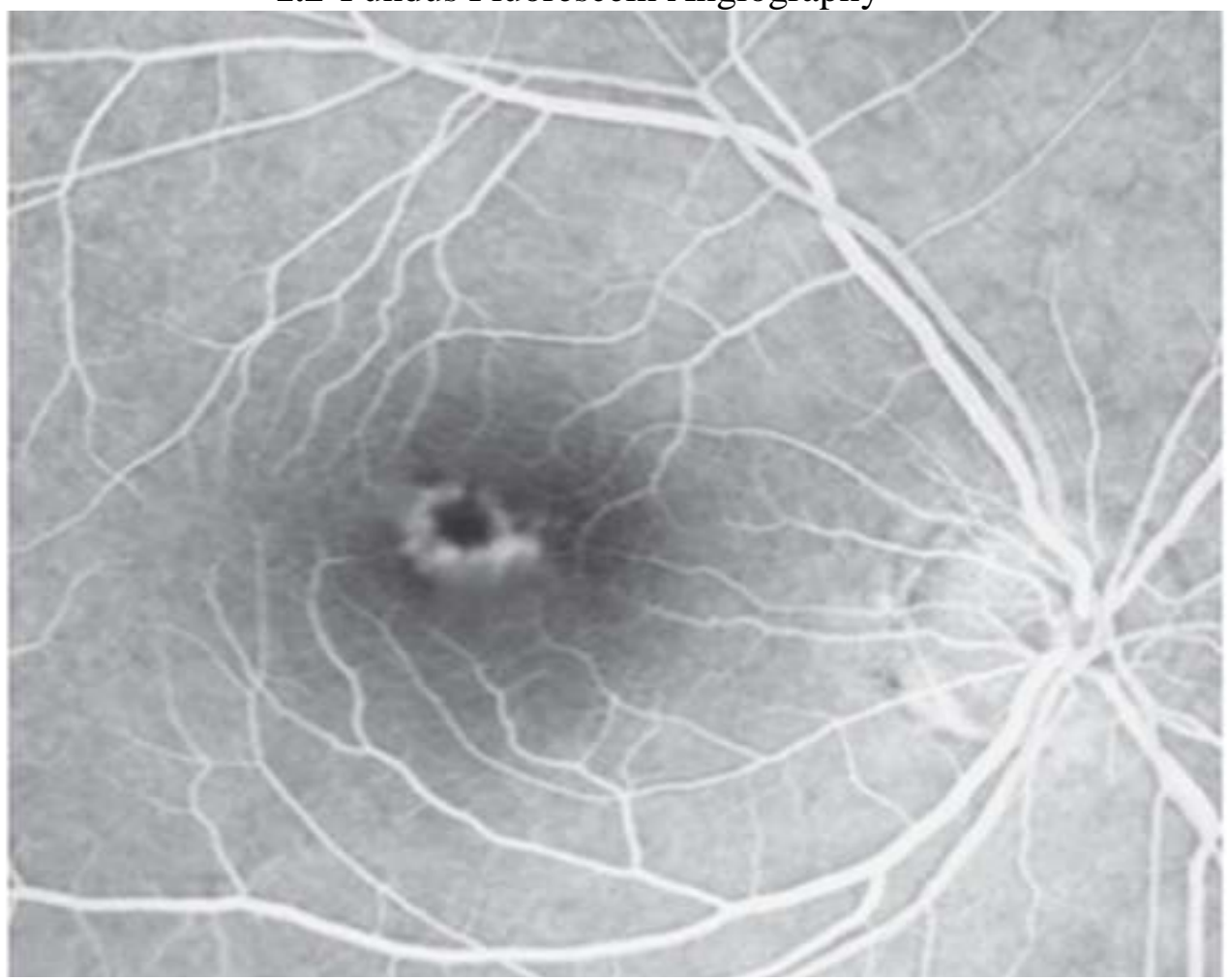

Figure 3: Right Eye -Arteriovenous Phase. Central Blockage With Ambient Hyperfluorescence.

(Centralhypofluroscence Surrounded By Ring Of Hyperfluroscence) 


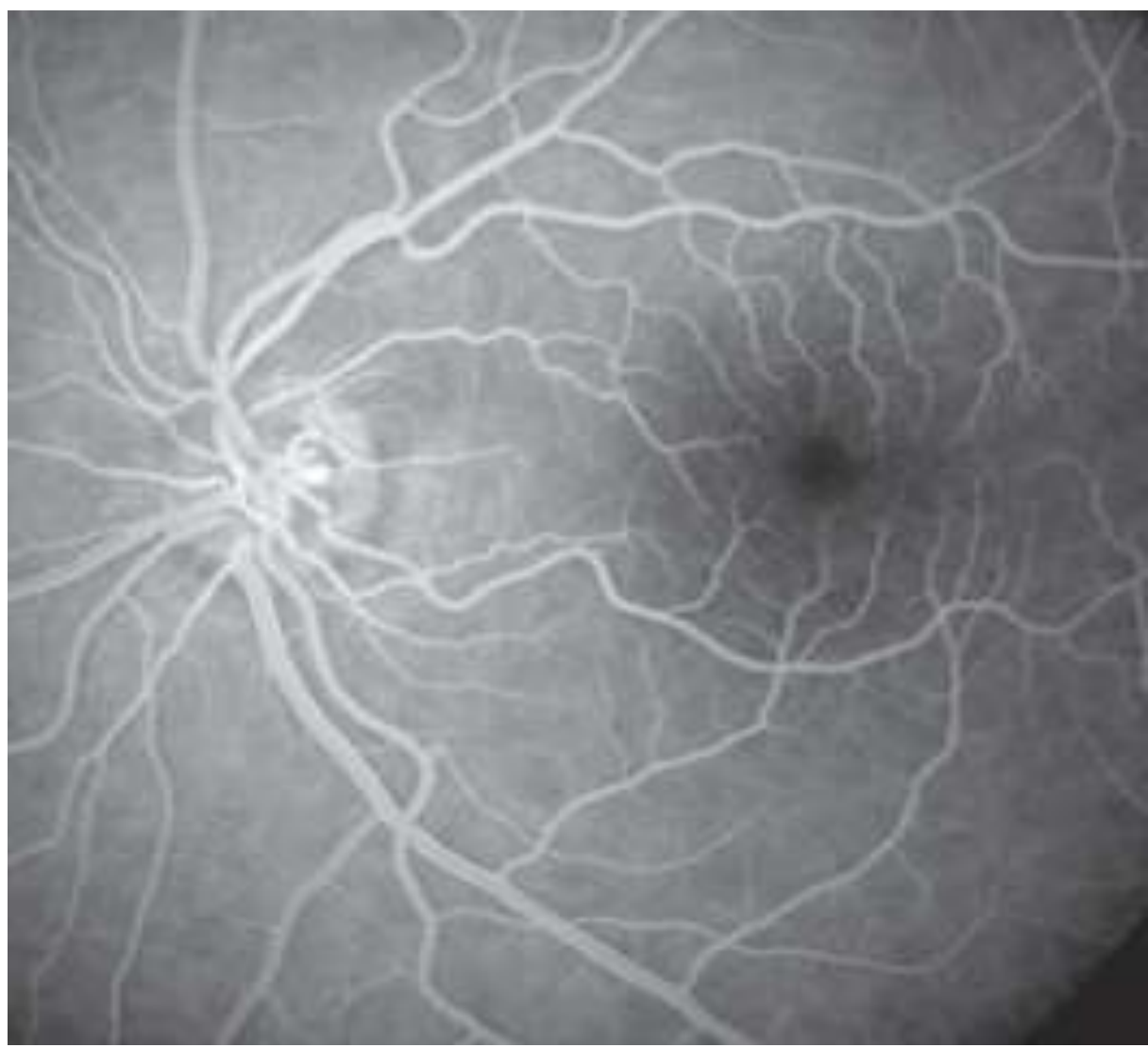

Figure 4: Left Eye- Appears With In Normal Limits.

1.3 Oct

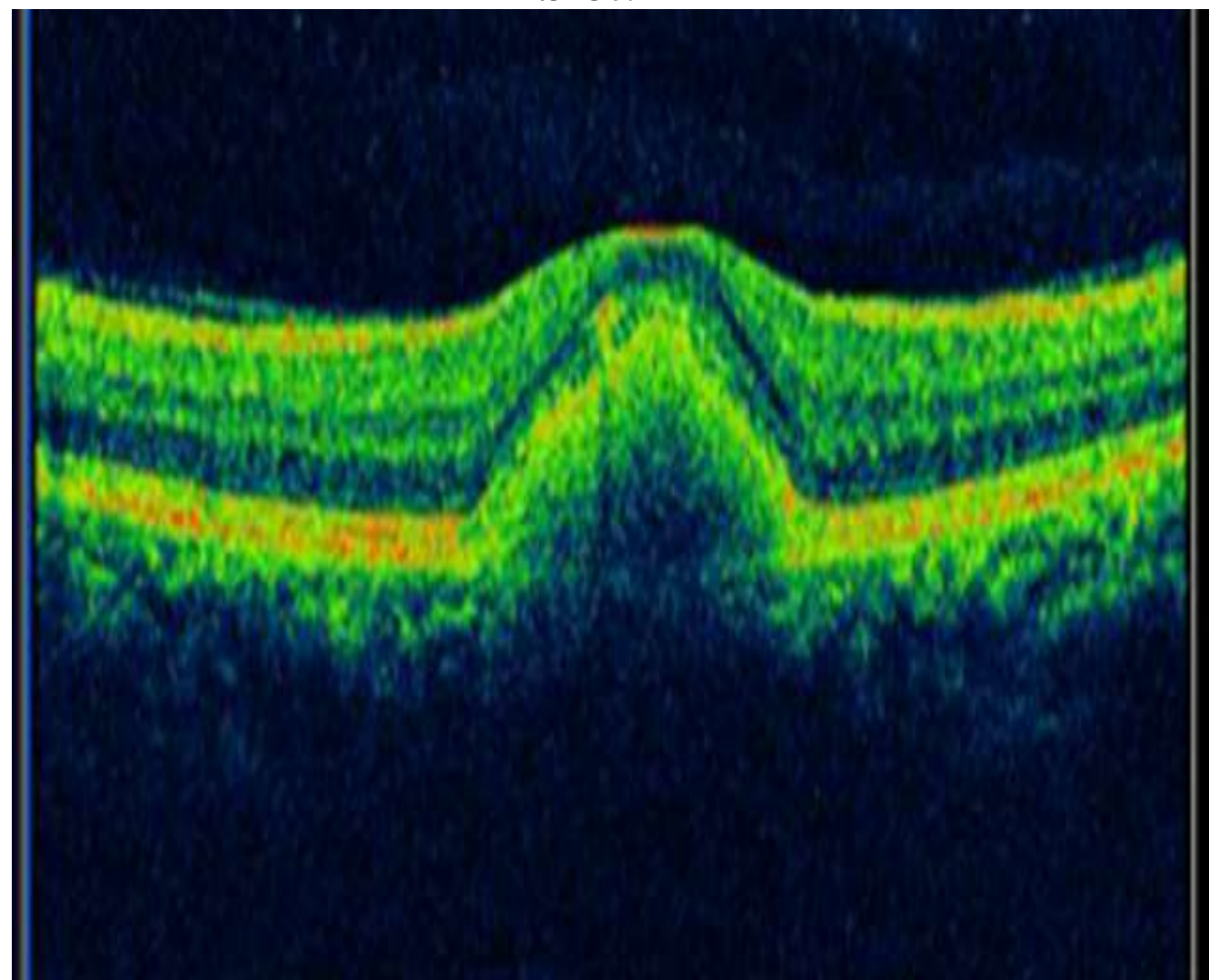

Figure 5: Right Eye- Subfoveal Deposit.Subretinalhper-Reflective Echo Causing Shadowing 


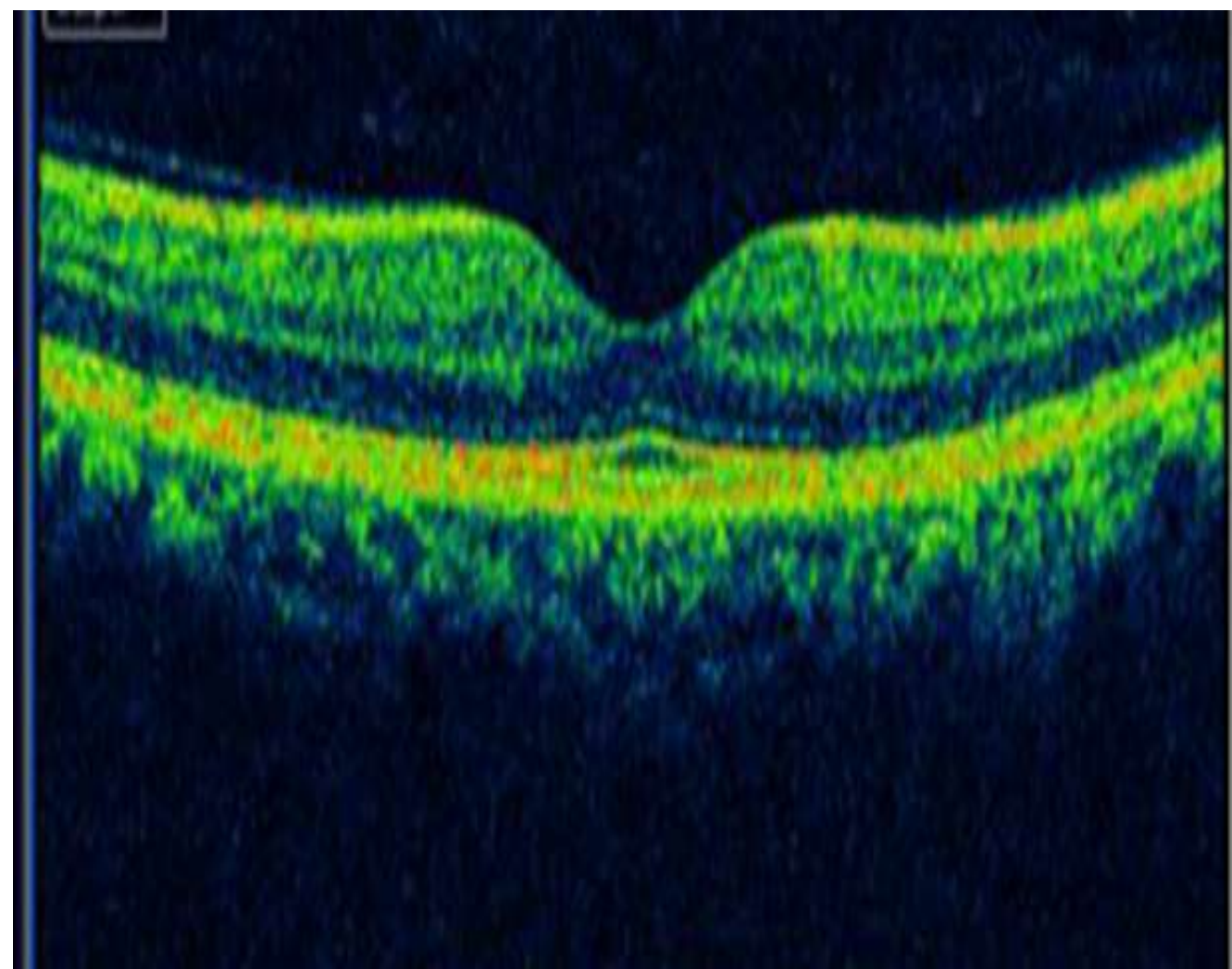

Figure 6: Left Eye- Appears With In Normal Limits.

1.4 EogIt Was Found To Be Normal. Ardens Ratio $\geq 1.8$.

\section{Discussion}

"Vitelliform" Macular Lesions Can Occur In A Variety Of Diseases That Affect The Rpe.

Broad Differential Diagnosis Exists, Ranging From Nonneovascular Amd And Cd To Acute Exudative Polymorphous Vitelliformmaculopathy (Aepvm).

In Our Case Fundus Findings (Fig 1) Were Supported By Ffa (Fig 3), Oct (Fig 5) And Eog ForAvmd.Avmd Is Known To Present With Variableexpressivity And Reduced Penetrance. Significant Asymmetry

Between Two Eyes Was Another Feature Of This Case.

\section{Conclusion}

Patients With Adult Onset Foveomacularvitelliform Dystrophy Typically Have Slow Progressive Vision Loss. However, Patients Can Develop Dramatically Decreased Vision Owing To Subfovealchoroidal Neovascularization (Cnv). Thus, It Is Important To Establish The Correct Diagnosis And Monitor This Condition. 


\section{References}

[1]. Gass Jdm. A Clinicopathologic Study Of A Peculiar Foveomacular Dystrophy. Trans Am Ophthalmolsoc 1974; 72: 139-156.

[2]. Gass Jdm. Stereoscopic Atlas Of Macular Diseases: Diagnosis And Treatment, 2nd Edn. Mosby-Year Book, Inc: St Louis, 1977, P 170.

[3]. Patrinely Jr, Lewis Ra, Font Rl. Foveomacularvitelliform Dystrophy, Adult Type. A Clinicopathologic Study Including Electron Microscopic Observations. Ophthalmology 1985; 92: 1712-1718.

[4]. Burgess Db, Olk Rj, Uniat Lm. Macular Disease Resembling Adult Foveomacularvitelliform Dystrophy In Older Adults. Ophthalmology 1987; 94: 362-366.

[5]. Vine Ak, Schatz H. Adult Onset Foveomacular Pigment Epithelial Dystrophy. Am J Ophthalmol 1980; 89: 680 .

[6]. Jaffe Gj, Schatz H. Histopathologic Features Of Adult-Onset Foveomacular Pigment Epithelial Dystrophy. Arch Ophthalmol 1988; 106: 958-960.

[7]. Dubovy Sr, Hairston Rj, Schatz H, Schachat Ap, Bressler Nm, Finkelstein D Et Al. Adult-Onset Foveomacular Pigment Epithelial Dystrophy. Clinicopathologic Correlation Of Three Cases. Retina 2000; 20: 638-649.

[8]. Epstein Ga, Rabb Mf. Adult Vitelliform Macular Degeneration: Diagnosis And Natural History. Br J Ophthalmol 1980; 64: 733.

[9]. Bloom Lh, Swanson De, Bird Ac. Adult Vitelliform Macular Degeneration. Br J Ophthalmol 1981; 65: 800.

[10]. Greaves Ah, Sarks Jp, Sarks Sh. Adult Vitelliform Macular Degeneration: A Clinical Spectrum. Aust Nz J Ophthalmol 1990; 18(2):171-178.

[11]. Gutman T, Walsh Jb, Henkind P. Vitelliform Macular Dystrophy And Butterfly-Shaped Epithelial Dystrophy: A Continuum? Br J Ophthalmol 1982; 66: 170-173.

[12]. Bernasconi Or, Piguet B. Pattern Dystrophies And Intrafamilial Phenotypic Variation. Klinmonatsblaugenheilkd 1996; 208(5): 291-293. 